\title{
High Frequency Laser-Based Ultrasound
}

R. Huber, D. Chinn, O. Balogun, T. Murray

September 28, 2005

2005 QNDE Conference

Brunswick, ME, United States

July 31, 2005 through August 5, 2005 
This document was prepared as an account of work sponsored by an agency of the United States Government. Neither the United States Government nor the University of California nor any of their employees, makes any warranty, express or implied, or assumes any legal liability or responsibility for the accuracy, completeness, or usefulness of any information, apparatus, product, or process disclosed, or represents that its use would not infringe privately owned rights. Reference herein to any specific commercial product, process, or service by trade name, trademark, manufacturer, or otherwise, does not necessarily constitute or imply its endorsement, recommendation, or favoring by the United States Government or the University of California. The views and opinions of authors expressed herein do not necessarily state or reflect those of the United States Government or the University of California, and shall not be used for advertising or product endorsement purposes. 


\title{
HIGH FREQUENCY LASER-BASED ULTRASOUND
}

\author{
R. D. Huber ${ }^{1}$, D. J. Chinn ${ }^{1}$, O. O. Balogun ${ }^{2}$, T. W. Murray ${ }^{2}$ \\ ${ }^{1}$ Lawrence Livermore National Laboratory, Livermore, CA 94550 \\ ${ }^{2}$ Boston University, Boston, MA 02215
}

\begin{abstract}
To obtain micrometer resolution of materials using acoustics requires frequencies around 1 GHz. Attenuation of such frequencies is high, limiting the thickness of the parts that can be characterized. Although acoustic microscopes can operate up to several GHz in frequency, they are used primarily as a surface characterization tool. The use of a pulsed laser for acoustic generation allows generation directly in the part, eliminating the loss of energy associated with coupling the energy from a piezoelectric transducer to the part of interest. The use of pulsed laser acoustic generation in combination with optical detection is investigated for the non-contact characterization of materials with features that must be characterized to micrometer resolution.
\end{abstract}

\section{INTRODUCTION}

Laser based ultrasonic (LBU) techniques for the generation and detection of acoustic waves have been used in a variety of nondestructive evaluation and materials characterization applications [1-11]. Pulsed lasers are typically used to generate the ultrasonic signals. The laser energy is absorbed at the sample surface where it causes rapid heating, thermal expansion, and ultrasonic wave production through the thermoelastic effect. Through evaluation of the velocity, dispersion characteristics, scattering, and attenuation of the ultrasonic waves, various physical and material properties can be determined. Laser ultrasonic techniques enjoy several advantages over other material characterization methods. The generation and detection lasers can be tightly focused on the sample surface allowing for high lateral resolution opening up the possibility of using laser ultrasonics to probe microscale structures. In addition, laser ultrasonic techniques can be used to probe structures in a completely nondestructive manner and without actually coming into contact with the structure.

At present, the majority of laser based ultrasonic work has been performed in one of two frequency regimes. In the first regime, traditional Q-switched laser sources, with pulse lengths in the $\sim 7-100 \mathrm{~ns}$ range, are used for ultrasound generation. These sources allow 
for the generation of acoustic waves in the $\mathrm{kHz}$ to 10 's of $\mathrm{MHz}$ frequency range. This bandwidth is suitable for a wide variety of NDE applications where the resolution requirements are on the order of $\sim 1 \mathrm{~mm}$. In the second regime, ultrafast laser pulses generated from mode-locked laser sources are used for ultrasound generation. Ultrafast laser sources produce femtosecond to low picosecond laser pulses. The pulses, in turn, can be used to generate acoustic waves with bandwidths in the 100's of GHz regime [11]. This frequency regime is of use in the semiconductor test and measurement sector for thin film analysis. The high frequency acoustic pulses generated by ultrafast sources may be used for acoustic imaging with a resolution in the 10's to 100's of nanometers range.

While ultrafast laser sources are capable of generating broad-bandwidth pulses, the high frequency components of these pulses are attenuated rapidly at room temperature in most materials. This restricts the depth at which subsurface structural features can be resolved. In addition, because the pulse energy is spread out over such a large frequency band, the acoustic energy available for materials inspection in the $\sim 1 \mathrm{GHz}$ range is limited. It is desirable to develop a laser based ultrasonic system, which can resolve micron scale structural features at depths on the order of several 100 microns. This requires the generation of acoustic waves with frequency components in the $500 \mathrm{MHz}-4 \mathrm{GHz}$ range, depending on the properties of the target material. One such application is the nondestructive characterization of National Ignition Facility (NIF) targets under development at the Lawrence Livermore National Laboratory. These targets have micrometer-sized features and millimeter-sized extents. In order to inspect these targets, a laser acoustic microscope has been developed that uses a Q-switched microchip laser for acoustic wave generation. Microchip lasers have pulse widths in the $\sim 300 \mathrm{ps}$ to 1 ns range making them well suited for the generation of $\mathrm{GHz}$ acoustic waves.

\section{LASER-BASED ACOUSTIC MICROSCOPE}

A schematic diagram of the laser-based acoustic microscopy system is shown in Figure 1. The system has three optical paths that lead to the sample surface through the same $20 \mathrm{x}$ objective $(\mathrm{NA}=0.4)$. The first path leads to a CCD camera and allows optical imaging of the sample surface as well as sample alignment. The system can be configured for same side generation and detection or through transmission experiments. In both cases, the detection laser light enters the microscope though a single mode optical fiber and is collimated. For same side experiments, a dichroic mirror (reflects at 532nm, transmits at $1064 \mathrm{~nm}$ ) is placed on the beam path and the detection probe reflects off of this mirror and is directed to the sample surface. For transmission experiments, a dichroic mirror that transmits at $532 \mathrm{~nm}$ and reflects at 1064 is used and the detection laser is directed through this mirror to the sample surface. Upon reflection from the sample the light is returned to a stabilized Michelson interferometer, and the interferometer output is sent to a digital storage scope. The detection laser is a $200 \mathrm{~mW}$ frequency doubled Nd:YAG $(\lambda=532 \mathrm{~nm})$.

The generation laser is a Nd:YAG microchip laser with a pulse energy of approximately $3 \mathrm{uJ}$ and a pulse width of $1 \mathrm{~ns}$. The laser is collimated, directed to a mirror on a gimbal mount, sent though a relay lens system, and directed to the specimen. The gimbal mount allows for precise control of the generation point within the field of view of the 


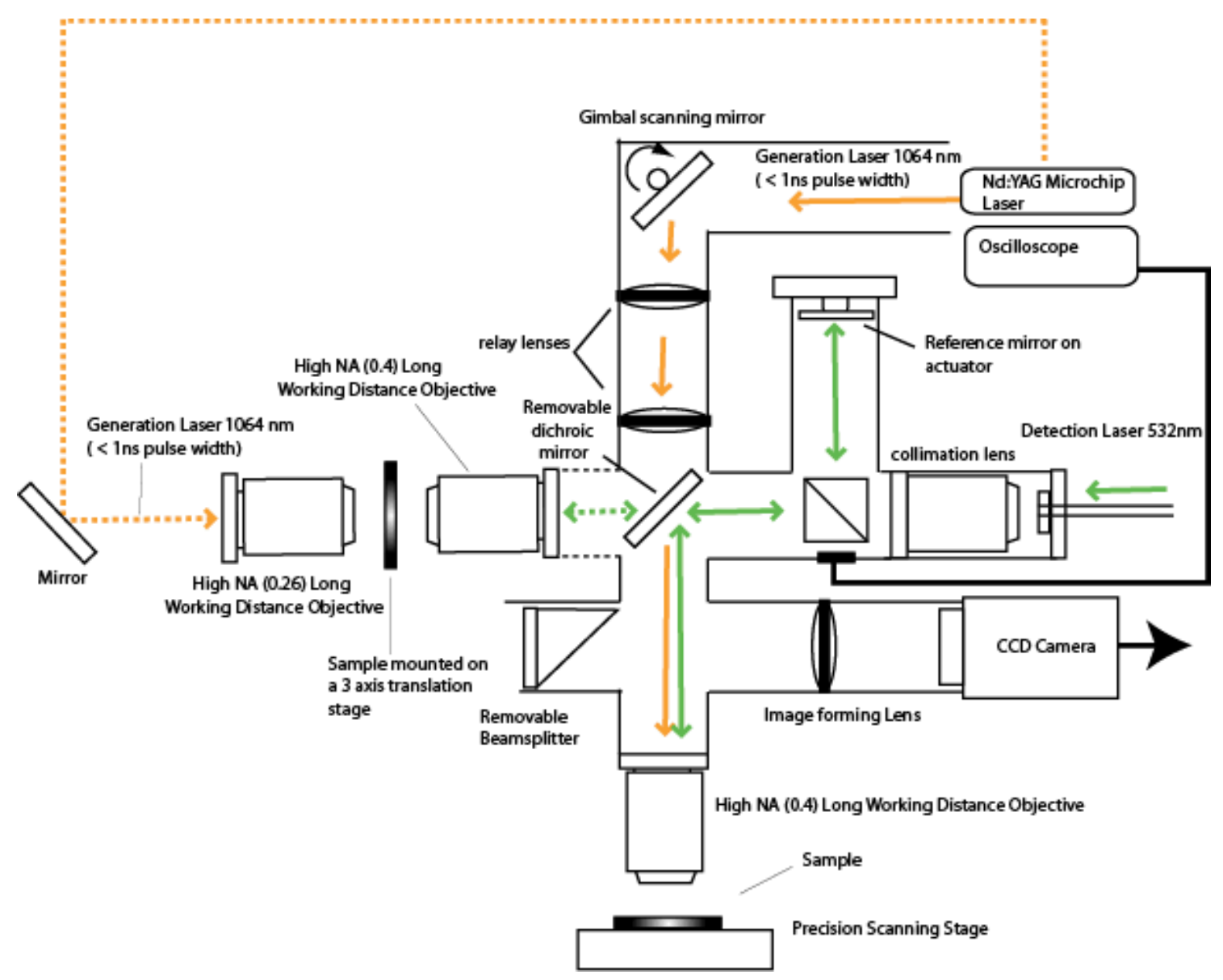

Figure 1. The Laser Based Acoustic Microscope. The dotted arrows show the optical path of the generation and detection lasers for through transmission experiments, while the solid arrows show the optical paths for the case of generation and detection of acoustic waves on the same side of the sample.

microscope. The total field of view of the microscope is $320 \times 240 \mu \mathrm{m}$. For the through transmission experiments, the detection laser is directed around the microscope assembly and through a $5 \mathrm{x}$ microscope objective (NA 0.26) to the sample surface.

\section{EXPERIMENTAL RESULTS}

Laser-ultrasonic waveforms were acquired on a number of metal foils in both the thermoelastic and ablative regimes. The goal of this preliminary set of experiments was to get an estimate of the maximum propagation distance at which the longitudinal wave arrival could be detected, and to investigate the frequency content of the longitudinal waves generated with a tightly focused microchip laser source in several materials of interest.

Figure 2 shows representative waveforms detected on a 100 um thick aluminum plate in through transmission. The top waveform is taken in the thermoelastic regime with a generation pulse energy of approximately $0.11 \mathrm{uJ}$ and a spot size of approximately $4 \mathrm{um}$. In 


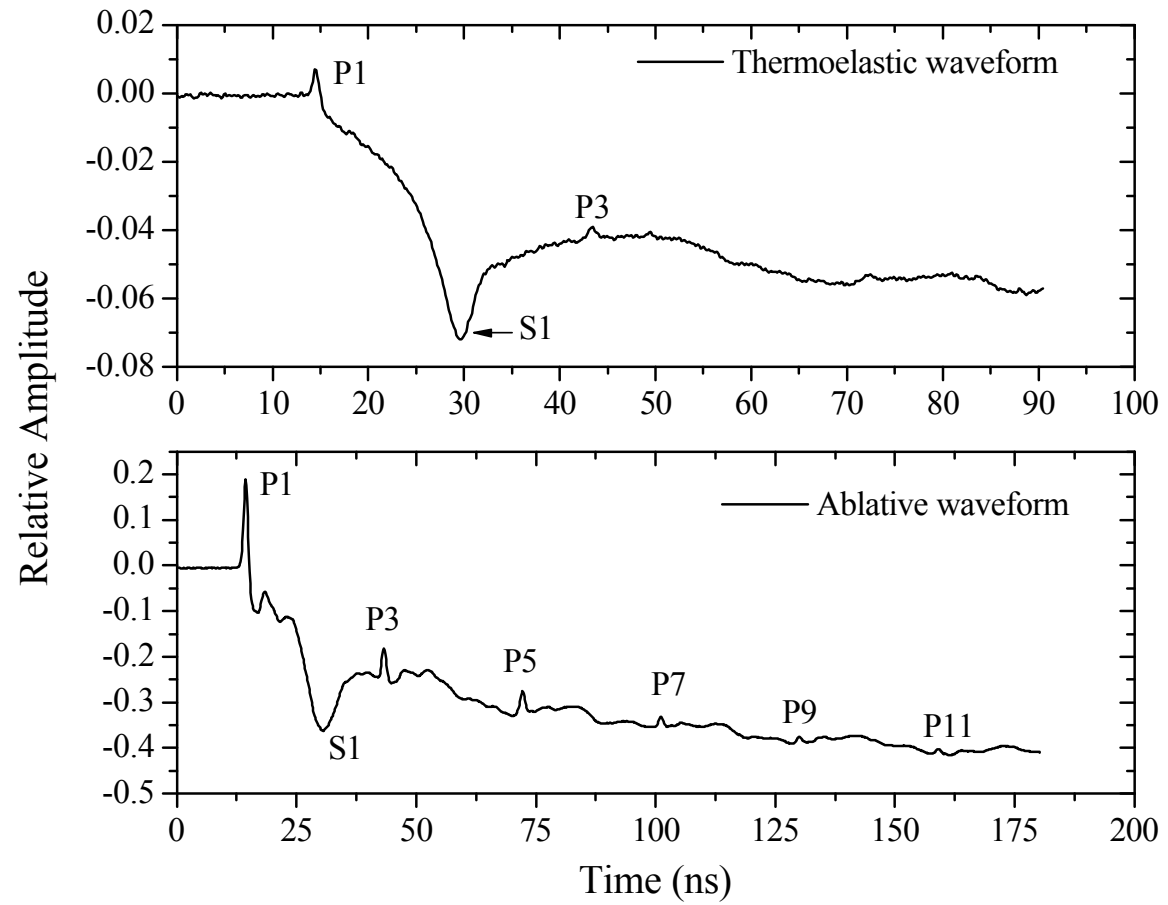

Figure 2. Through transmission laser generated acoustic waves measured on epicenter in a $100 \mu \mathrm{m}$ thick aluminum plate. Data shows the arrival of longitudinal waves denoted by P and a shear wave arrival denoted by $\mathrm{S}$.

this case the first 2 longitudinal arrivals corresponding to one (P1) and three (P3) passes through the specimen are observed. The full width at half maximum of the first longitudinal wave arrival is less than $1 \mathrm{~ns}$. The bottom waveform shows the waveform detected when the laser pulse energy is increased to $0.13 \mathrm{uJ}$. In this case, the ablation threshold is reached and longitudinal arrivals corresponding to 11 passes through the specimen are observed.

Waveforms were also gathered on several polymer films. In order to provide an interface at which the generation laser could be absorbed and a reflective surface for the detection probe, the samples were sputter coated with metal layers ( $\mathrm{Al}, \mathrm{Cr}$ ) of various thicknesses (50 $\mathrm{nm}, 80 \mathrm{~nm} 200 \mathrm{~nm}$ ). On the polymer samples, the generation laser energy was kept in the thermoelastic regime. Waveforms above the ablation threshold led to removal of the thin coating material. Figure 3 shows a representative waveform detected in through transmission mode in a 100um polystyrene sample. The sample was coated on both sides with $100 \mathrm{~nm}$ of aluminum. Longitudinal wave arrivals corresponding to up to seven passes through the specimen are observed.

One final set of experimental results are presented demonstrating system operation with same side, near-epicentral generation and detection. In this case, the sample is a $0.25 \mathrm{~mm}$ thick gold foil. The source was displaced a few microns from the detector and the laser energy was turned up such that the generation mechanism was slightly ablative. Figure 4(a) 


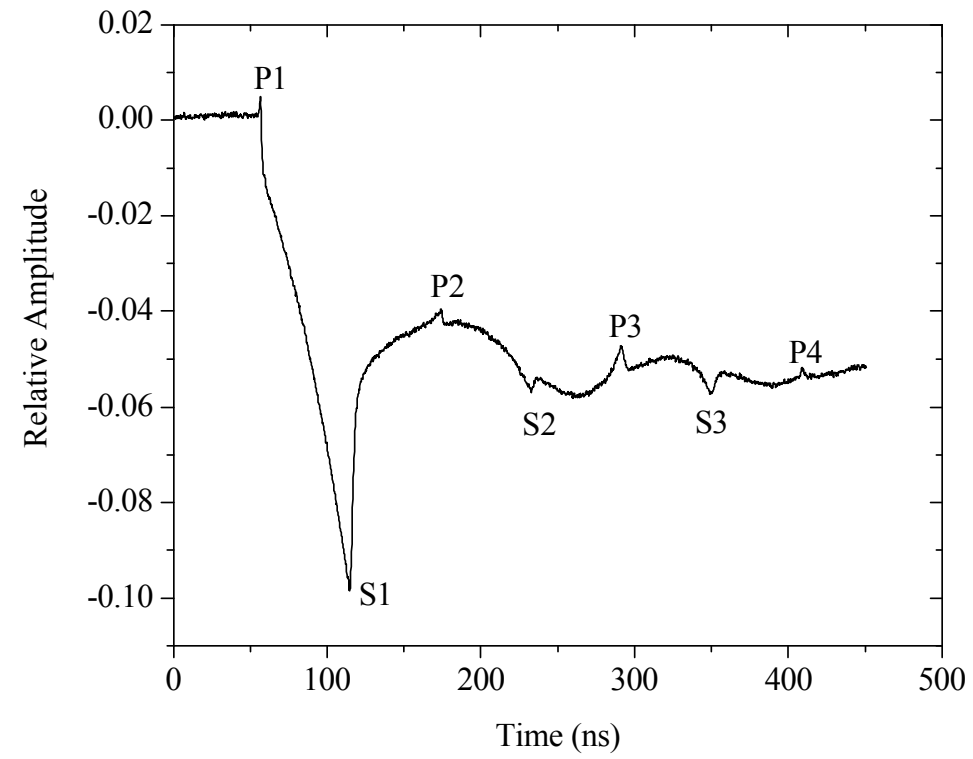

Figure 3. Measured through transmission waveforms generated on epicenter by the laser source in a $125 \mu \mathrm{m}$ thick polystyrene plate with a $100 \mathrm{~nm}$ thick aluminum film on both sides of the sample.

shows the raw displacement waveform. The large low frequency background is due to thermoelastic expansion of the surface. Figure 4(b) shows the waveform after filtering with a $200 \mathrm{MHz}$ high-pass filter. In this figure, there is a surface wave arrival, followed by 10 longitudinal arrivals. Two small segments of the waveform were windowed around the first and second longitudinal arrivals. The power spectra for these two windows were calculated and are shown in Figure 4(c). The spectra show a frequency peak of approximately $400 \mathrm{MHz}$ and show that there are frequency components exceeding $1 \mathrm{GHz}$ in these arrivals. Preliminary measurements have been performed on the following materials: aluminum, copper, vanadium, gold, tantalum, polystyrene, polycarbonate, and polyamide. These are all candidate materials for future NIF target applications. In all of these samples, we have been able to detect longitudinal wave arrivals generated in the thermoelastic regime after propagating greater than $100 \mathrm{um}$, and with frequency components high enough to resolve feature sizes below $10 \mathrm{um}$. In some materials, such as aluminum frequency components in the $700 \mathrm{MHz}-1 \mathrm{GHz}$ have been detected after a propagation distance of several hundred microns. Note that the decay in acoustic wave amplitude (see Figure 2, for example) is due primarily to geometric spreading. In addition, energy is lost through grain boundary scattering and material attenuation. The results presented here are strongly related to the material microstructure. Finally, the inspection of the transparent polymers required thin coatings to be applied to absorb the generation laser energy and reflect the detection laser probe. While this is not ideal for nondestructive testing of NIF target, it may be possible to develop coatings that are easily removed subsequent to inspection without causing damage to the substrate. 

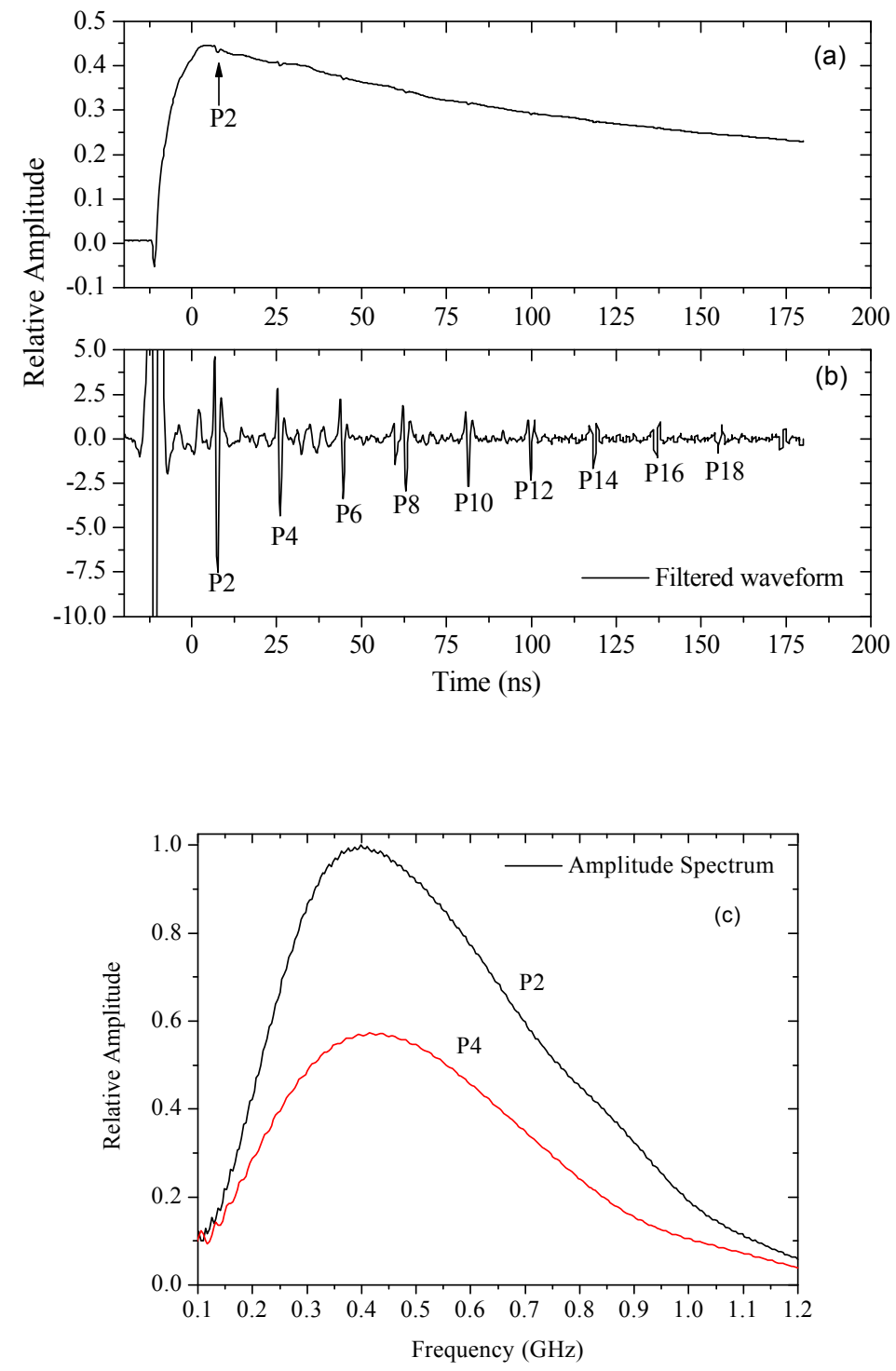

Figure 4. (a) Epicentral waveform obtained in a $25 \mu \mathrm{m}$ thick gold foil with the source and probe laser collocated on the same side of the sample. (b) High pass filtered waveform shows the arrival of longitudinal waves labeled P2 to P18. (c) Amplitude spectrum of the first and second longitudinal wave arrivals P2 and P4 shown in Figure 2(b).

\section{CONCLUSIONS}

The propagation distances achieved for $800 \mathrm{MHz}$ longitudinal mode ultrasound through the materials investigated in this work indicate that mesoscale characterization using laserbased ultrasound is possible. Although the ablative generation regime yields much better 
signal-to-noise, the thermoelastic regime yields signal amplitudes that are adequate for mesoscale testing.

\section{ACKNOWLEDGEMENTS}

This work was performed under the auspices of the U.S. Department of Energy by the University of California, Lawrence Livermore National Laboratory under Contract No. W7405-Eng-48.

\section{REFERENCES}

1. C.B. Scruby and L.E. Drain, Laser Ultrasonics, Techniques and Applications, Adam Hilger, N.Y. (1990).

2. S.J. Davies, C. Edwards, G.S. Taylor, and S.B. Palmer, "Laser-generated ultrasound: its properties, mechanisms, and multifarious applications," J. Phys. D 26 329-348 (1993).

3. J.P. Monchalin, C. Neron, J.F. Bussiere, P. Bouchard, C. Padioleau ,R. Heon, M. Choquet , J.D. Aussel, G. Durou, and G. Nilson, "Laser-ultrasonics: From the laboratory to the shop floor," Adv. Perform. Mater. 5 (1-2) 7-23 (1998).

4. T.W. Murray, S. Krishnaswamy, and J.D. Achenbach, "Laser generation of ultrasound in films and coatings", Appl. Phys. Lett. 74 (23), 3561-3563 (1999).

5. J.A. Rogers, "Optical Generation and Characterization of Acoustic waves in Thin Films: Fundamentals and Applications," Annu. Rev. Mater. Sci. 30 117-157 (2000).

6. C. Hernandez, T.W. Murray, and S. Krishnaswamy, "Photo-acoustic characterization of the Mechanical Properties of Thin Films," Appl. Phys. Lett. 80 (4) (2002).

7. G. Lehmann, P. Hess, S. Weissmantel, G. Reisse, P. Scheible, and A. Lunk, "Young's modulus and density of nanocrystalline cubic boron nitride films determined by dispersion of surface acoustic waves," Appl. Phys. A 74 (1) 41-45 (2002).

8. D. Schneider, H. Ollendorf, and T. Schwartz, "Non-destructive evaluation of the mechanical behavior of TiN-coated steels by laser induced ultrasonic waves," Appl. Phys. A 61, 277-284 (1995).

9. M.J. Banet, M. Fuchs, J.A. Rogers, J.H. Reinild Jr., J.M. Knecht, M. Rothschild, R. Logan, A.A. Maznev, and K.A. Nelson," High Precision film thickness determination using a laser-based ultrasonic technique," Appl. Phys. Lett. 73 (2) 169-171 (1998).

10. M.J. Banet, M. Fuchs, J.A. Rogers, J.H. Reinild Jr., J.M. Knecht, M. Rothschild, R. Logan, A.A. Maznev, and K.A. Nelson," High Precision film thickness determination using a laser-based ultrasonic technique," Appl. Phys. Lett. 73 (2) 169-171 (1998).

11. Thomsen, C., Grahn, H.T., Maris, H.J., and Tauc, J. (1986) Surface generation and detection of phonons by picosecond light pulses, Phys. Rev. B 34(6) pp. 4129. 